OPEN ACCESS

Edited by:

Jinsong Bian,

National University of Singapore,

Singapore

Reviewed by:

Li-Fang $\mathrm{Hu}$,

Soochow University, Taiwan

Yahong Chen

Peking University Third Hospital,

China

${ }^{*}$ Correspondence:

Liu Yang

lucy02114@163.com

Specialty section:

This article was submitted to

Experimental Pharmacology and Drug

Discovery,

a section of the journal

Frontiers in Pharmacology

Received: 25 June 2017 Accepted: 15 August 2017

Published: 29 August 2017

Citation:

Du J, Jin H and Yang L (2017) Role of Hydrogen Sulfide in Retinal

Diseases. Front. Pharmacol. 8:588. doi: 10.3389/fphar.2017.00588

\section{Role of Hydrogen Sulfide in Retinal Diseases}

\author{
Jiantong Du ${ }^{1}$, Hongfang Jin $^{2}$ and Liu Yang ${ }^{1 *}$ \\ 'Department of Ophthalmology, Peking University First Hospital, Beijing, China, ${ }^{2}$ Department of Pediatrics, Peking University \\ First Hospital, Beijing, China
}

As the third gasotransmitter, hydrogen sulfide $\left(\mathrm{H}_{2} \mathrm{~S}\right)$ plays a crucial role in the physiology and pathophysiology of many systems in the body, such as the nervous, cardiovascular, respiratory, and gastrointestinal systems. The mechanisms for its effects, including inhibiting ischemic injury, reducing oxidative stress damage, regulating apoptosis, and reducing the inflammation reaction in different systems, have not been fully understood. Recently, $\mathrm{H}_{2} \mathrm{~S}$ and its endogenous synthesis pathway were found in the mammalian retina. This review describes the production and the metabolism of $\mathrm{H}_{2} \mathrm{~S}$ and the evidence of a role of $\mathrm{H}_{2} \mathrm{~S}$ in the retina physiology and in the different retinal diseases, including retinal degenerative diseases and vascular diseases. In the retina, $\mathrm{H}_{2} \mathrm{~S}$ is generated in the presence of cystathionine- $\beta$-synthase, cystathionine- $\gamma$-lyase, and 3-mercaptopyruvate sulfurtransferase from L-cysteine. The role of endogenous $\mathrm{H}_{2} \mathrm{~S}$ and its physiologic effect in the retina are still elusive. However, strong evidence shows that retina-derived $\mathrm{H}_{2} \mathrm{~S}$ might play protective or deleterious role in the pathogenesis of retinal diseases. For example, by regulating $\mathrm{Ca}^{2+}$ influx, $\mathrm{H}_{2} \mathrm{~S}$ can protect retinal neurons against light-induced degeneration. $\mathrm{H}_{2} \mathrm{~S}$ preconditioning can mediate the antiapoptotic effect of retinal ganglion cells in retinal ischemia/reperfusion injury. Treatment with $\mathrm{H}_{2} \mathrm{~S}$ in rats relieves diabetic retinopathy by suppressing oxidative stress and reducing inflammation. Further studies would greatly improve our understanding of the pathophysiologic mechanisms responsible for retinal diseases and the potential for the $\mathrm{H}_{2} \mathrm{~S}$-related therapy of the retinal diseases as well.

Keywords: $\mathrm{H}_{2} \mathrm{~S}$, neuromodulator, physiology, pathology, retinal vascular diseases, retinal degenerative diseases

\section{INTRODUCTION}

Hydrogen sulfide $\left(\mathrm{H}_{2} \mathrm{~S}\right)$, a well-known toxic gas characterized by its "rotten-egg" smell, has attracted substantial interest for its non-toxic effects in mammals. $\mathrm{H}_{2} \mathrm{~S}$ was considered as an important gasotransmitter since Abe and Kimura (1996) discovered the enzymatic reaction process of $\mathrm{H}_{2} \mathrm{~S}$ generation in the brain tissues along with its biological activity at a physiological concentration. Since then, the gasotransmitter $\mathrm{H}_{2} \mathrm{~S}$ has been found to be involved physiologically and pathologically in the neuroregulation (Pérez-H et al., 2014), vasodilatation (Hosoki et al., 1997), endocrinologic regulation (Kaneko et al., 2006), and inflammation (Du et al., 2014), etc. 
Recently, strong evidence has shown the presence of $\mathrm{H}_{2} \mathrm{~S}$ and its endogenous synthesis pathway in the mammalian retina. This review presents the production of endogenous $\mathrm{H}_{2} \mathrm{~S}$ and the evidence of its role in the retinal physiology and different retinal diseases including the retinal degenerative and vascular diseases, and the underlying mechanism (Figure 1).

\section{$\mathrm{H}_{2} \mathrm{~S}$ GENERATION IN THE RETINAL TISSUES}

So far, four enzymatic pathways that regulate endogenous $\mathrm{H}_{2} \mathrm{~S}$ production have been revealed: cystathionine- $\beta$-synthase (CBS), cystathionine- $\gamma$-lyase (CSE) (Stipanuk and Beck, 1982; Abe and Kimura, 1996), cysteine aminotransferase/3-mercaptopyruvate sulfurtransferase (CAT/3MST) (Hughes et al., 2009) and D-amino acid oxidase (DAO)/3MST (Shibuya et al., 2013). However, only the first three endogenous $\mathrm{H}_{2} \mathrm{~S}$ synthesis pathways have been reported to be involved in the retinal tissue, and there is no report of DAO/3MST pathways present in retinal tissue. The results of the distribution of the endogenous $\mathrm{H}_{2} \mathrm{~S}$ synthesis and regulation in retinal tissue are controversial due to the different species and methods used in the study. Pong et al. (2007) found the expression and activity of CBS and CSE in the retinal tissue of salamander and those of CSE in the retinal tissue of mice. Mikami et al. (2011) detected the expression of endogenous $\mathrm{H}_{2} \mathrm{~S}$ producing enzymes in each layer of the retina in mice by immunohistochemistry. The result showed that 3MST and CAT were expressed in the inner plexiform layer, outer plexiform layer, inner nuclear layer, outer nuclear layer, and outer segments of photoreceptors of the retina, with the absence of CBS and CSE, which suggests that $\mathrm{H}_{2} \mathrm{~S}$ generation might be catalyzed almost by the CAT/3MST pathway in the mouse retina (Mikami et al., 2011). Gersztenkorn et al. (2016) further confirmed CBS, CSE, and 3MST protein expression in mouse retinal tissue by Western blot and immunohistochemistry. Kulkarni et al. (2011) used inhibitors of $\mathrm{H}_{2} \mathrm{~S}$-producing enzymes to study the endogenous $\mathrm{H}_{2} \mathrm{~S}$ synthesis pathway in the bovine retina and the results showed that the use of CBS inhibitor or the use of CSE inhibitor, or the combined application of CBS and CSE inhibitors could not completely block the endogenous $\mathrm{H}_{2} \mathrm{~S}$ generation in bovine retina, which indicated that perhaps other enzymes apart from $\mathrm{CSE}$ and $\mathrm{CBE}$ might contribute to $\mathrm{H}_{2} \mathrm{~S}$ generation in bovine retina.

\section{EFFECT OF $\mathrm{H}_{2} \mathrm{~S}$ ON RETINAL PHYSIOLOGY}

In the central nervous system (CNS), $\mathrm{H}_{2} \mathrm{~S}$ has been reported to regulate synaptic activities as a neurotransmitter (Kimura et al., 2005). However, $\mathrm{Qu}$ et al. (2006) found that $\mathrm{H}_{2} \mathrm{~S}$ acted as a mediator of ischemic injury on neurons and the inhibition of endogenous $\mathrm{H}_{2} \mathrm{~S}$ production would be a potential neuroprotective strategy for stroke. Ion channels and transporters were found to be involved in the regulatory effects of $\mathrm{H}_{2} \mathrm{~S}$ on CNS (Tang et al., 2010; Kimura, 2011). We have few studies of the physiologic effects of $\mathrm{H}_{2} \mathrm{~S}$ in the retina, but the presence of $\mathrm{H}_{2} \mathrm{~S}$ and its endogenous synthesis pathway in the retina as well as the fact that deficiency of CBS may lead to retinal degeneration and detachment (Kraus and Kozich, 2001) both indicate that $\mathrm{H}_{2} \mathrm{~S}$ plays an important role in the eye as a gaseous neuromodulator.

\section{Effect of $\mathrm{H}_{2} \mathrm{~S}$ on Ion Channels in the Retina}

Potassium channels including ATP-sensitive potassium channel $\left(\mathrm{K}_{\mathrm{ATP}}\right)$ are important to the physiologic role of $\mathrm{H}_{2} \mathrm{~S}$ (Zhao et al., 2001; Geng et al., 2004). Given the well-known regulatory effect of potassium channels in the retina (Cordeiro et al., 2011), it is reasonable to hypothesize that $\mathrm{H}_{2} \mathrm{~S}$ modulates retinal function by acting on the potassium channel. Njie-Mbye et al. found that glibenclamide, a $\mathrm{K}_{\mathrm{ATP}}$ channel inhibitor, inhibited the $\mathrm{H}_{2} \mathrm{~S}$ donor NaHS-induced cyclic adenosine monophosphate (cAMP) formation in rat retinal pigment epithelial (RPE) cells, suggesting that $\mathrm{K}_{\mathrm{ATP}}$-channel might be involved in the effect of $\mathrm{H}_{2} \mathrm{~S}$ on the cAMP-related RPE cell proliferation, apoptosis, and phagocytosis (Njie-Mbye et al., 2012). NaHS was found to have a prominent relaxation effect on the retina arteries by acting on the voltage-dependent potassium channel $\left(\mathrm{K}_{\mathrm{V}}\right)$ and inwardly rectifying potassium channel $\left(\mathrm{K}_{\mathrm{ir}}\right)$ (Takır et al., 2015), indicating that $\mathrm{H}_{2} \mathrm{~S}$ may play an important role in regulating the retina vascular system.

The calcium transport system exists in retinal Müller cells as well as RPE (Bringmann et al., 2000; Wimmers et al., 2006), and the change in these channels may contribute to the retinal degenerative diseases (Wimmers et al., 2006). Mikami et al. (2011) found that intracellular $\mathrm{Ca}^{2+}$ inhibited CAT/3MSTderived $\mathrm{H}_{2} \mathrm{~S}$ production in retinal lysates and in turn $\mathrm{H}_{2} \mathrm{~S}$ blocked high $\mathrm{K}^{+}$-induced $\mathrm{Ca}^{2+}$ influx via activating $\mathrm{V}$-ATPase in the outer nuclear layer (ONL) and outer plexiform layer (OPL). The counteraction between the $\mathrm{H}_{2} \mathrm{~S}$ and intracellular $\mathrm{Ca}^{2+}$ in the retina mediated the protective effect of $\mathrm{H}_{2} \mathrm{~S}$ on the retinal photoreceptor apoptosis caused by excessive light (Mikami et al., 2011).

Besides $\mathrm{K}^{+}$and $\mathrm{Ca}^{2+}$ channels, other ion channels such as sodium and chloride channels are believed to have an important effect on various physiologic processes in the retina (Zhang et al., 2011; Smith et al., 2017). However, whether $\mathrm{H}_{2} \mathrm{~S}$ acts on the sodium and chloride channels has not been clear yet. Therefore, further studies need to be done to explore the possible relationship between retina-derived $\mathrm{H}_{2} \mathrm{~S}$ and the ion channels.

\section{Regulation of Neurotransmission by $\mathrm{H}_{2} \mathrm{~S}$ in the Retina}

Glutamate is an important neurotransmitter and plays a key role in the fast excitatory synaptic transmission in the CNS. Therefore, glutamate has been reported to be implicated in the physiologic processes such as neuronal development and synaptic plasticity and pathophysiologic processes such as excitotoxicity (Seki et al., 2010). $\left[{ }^{3} \mathrm{H}\right] \mathrm{D}$-aspartate is a substitute for glutamate in neurotransmitter release assay. Opere et al. (2009) found that both $\mathrm{NaHS}$ and $\mathrm{Na}_{2} \mathrm{~S}$ donors inhibited high $\mathrm{K}^{+}$-evoked 
$\left[{ }^{3} \mathrm{H}\right] \mathrm{D}$-aspartate release from isolated bovine and porcine retinae. Although the mechanisms were unclear, but it is supposed that there might be an involvement of glutamate aspartate transporter which lowers the extracellular glutamate level to protect the neurons against excitotoxic damage. One study suggested that a derivative of latanoprost acid (ACS67), which can release $\mathrm{H}_{2} \mathrm{~S}$, had a remarkable effect on increasing glutathione (GSH) and cyclic guanosine monophosphate (cGMP) levels in the aqueous humor (Perrino et al., 2009). In the retina, the glutamate aspartate transporter is located in Müller cells and maintains the level of GSH with the toxic effects of glutamate (Martin et al., 2012). Therefore, this transporter might be a target of $\mathrm{H}_{2} \mathrm{~S}$ to regulate neurotransmission in the retina. Future studies of the exact mechanisms are needed.

\section{EFFECT OF $\mathrm{H}_{2} \mathrm{~S}$ ON RETINAL PATHOLOGY}

Retinal diseases including retinal degenerative diseases and vascular diseases have become the leading causes of blindness reported by the World Health Organization (Pascolini and Mariotti, 2012). Their irreversible damage to vision and refractory characteristics make them a hot topic for ophthalmologists all over the world. Here, we discuss the effects of $\mathrm{H}_{2} \mathrm{~S}$ on retinal degenerative diseases and vascular diseases.

\section{$\mathrm{H}_{2} \mathrm{~S}$ and Retinal Degenerative Diseases}

Retinal degenerative diseases, commonly including retinitis pigmentosa (RP), age-related macular degeneration (AMD), and glaucomatous retinal neuropathy, share the main pathological basis of abnormal structure and function of retinal neurons at all levels, which results in an irreversible damage to visual acuity (Cottet and Schorderet, 2009).

Progressive degeneration of the photoreceptor cells in the retina contributes to the severe visual injury of RP and AMD (Busskamp et al., 2010). The photoreceptor cell apoptosis is a key pathologic basis of human retinal degeneration and lightinduced retinal degeneration models (Wenzel et al., 2005; Rajala and Rajala, 2013). In one study, NaHS administration suppressed the light-induced photoreceptor degeneration in association with decreasing photoreceptor cell apoptosis and DNA damage in the retinal ONL in a mice retinal degeneration model caused by excessive light exposure. Simultaneously, NaHS prevented high $\mathrm{K}^{+}$-evoked $\mathrm{Ca}^{2+}$ influx in mice retinal ONL and OPL (Mikami et al., 2011), suggesting that restoring $\mathrm{Ca}^{2+}$ homeostasis might be involved in the protective effect of $\mathrm{H}_{2} \mathrm{~S}$ on the photoreceptor cell apoptosis. The above findings indicate that $\mathrm{H}_{2} \mathrm{~S}$ might act as a neuroprotector to prevent from retinal degeneration. On the other hand, abnormal function of RPE cells is an important pathological process of RP and AMD (Da et al., 2007; Liu et al., 2015). $\mathrm{H}_{2} \mathrm{~S}$ donor $\mathrm{NaHS}$ and endogenous $\mathrm{H}_{2} \mathrm{~S}$ were found to dose-dependently increase cAMP concentrations in rat RPE cells (Njie-Mbye et al., 2010), while the increase in intracellular cAMP level resulted in the downregulation of phagocytic activity of RPE cells, which would lead to the progression of RP and AMD (Hall et al., 1993; Kuriyama et al., 1995). The above facts suggest that
$\mathrm{H}_{2} \mathrm{~S}$ might aggravate the process of RP and AMD. Collectively, whether $\mathrm{H}_{2} \mathrm{~S}$ has a protective or deleterious effect on RP and AMD needs further research.

Although glaucoma is not usually described as a retinal disease, glaucomatous retinal neuropathy is the leading cause of vision impairment in glaucoma (Low et al., 2015). Recently, $\mathrm{H}_{2} \mathrm{~S}$ levels and expression of its endogenous enzymes CBS, CSE, and $3 \mathrm{MST}$ in retinal tissues were significantly decreased along with the loss of retinal ganglion cells (RGCs) in a chronic ocular-hypertension rat model. While the treatment with NaHS could improve the survival of RGCs without impacting on the intraocular pressure (Huang et al., 2017). However, Perrino et al. (2009) found that $\mathrm{H}_{2} \mathrm{~S}$-releasing agent ACS67 reduced the intraocular pressure in carbomer-induced glaucoma in rabbits and increased the GSH and cGMP content in aqueous humor. The above interesting results give a better understanding of the pathogenesis of glaucomatous retinal neuropathy and provide a potential therapeutic target for glaucoma.

\section{$\mathrm{H}_{2} \mathrm{~S}$ and Retinal Vascular Diseases}

Retinal vascular diseases are defined as diseases first caused by a retinal vascular abnormality, which leads to injured retinal neurons or vision. The diseases mainly include retinal artery occlusion (RAO), retinal vein occlusion (RVO), and diabetic retinopathy (DR).

In retinal vascular occlusion, including RAO and RVO, ischemia/reperfusion (I/R) injury plays a significant role in the pathologic process (Archer, 1976). It causes RGCs death by inducing apoptosis and necrosis (Hayreh et al., 2004). Intravitreal injection of the $\mathrm{H}_{2} \mathrm{~S}$ donor ACS67 could prevent the retinal injury caused by elevated intraocular pressure-induced retina I/R in an in vivo experiment. Furthermore, in vitro study showed that ACS67 suppressed $\mathrm{H}_{2} \mathrm{O}_{2}$-induced RGC-5 cell apoptosis and improved RGC-5 cell viability via increasing the GSH level and decreasing reactive oxygen species level (Osborne et al., 2010). Biermann et al. (2011) found that inhaled $\mathrm{H}_{2} \mathrm{~S}$ preconditioning attenuated RGC death after retina I/R injury. NF- $\kappa$ B ERK/MAPK, and JNK/MAPK pathways were involved in the anti-apoptotic mechanisms for $\mathrm{H}_{2} \mathrm{~S}$ preconditioning (Biermann et al., 2011). Additionally, $\mathrm{H}_{2} \mathrm{~S}$ could relax retinal arteries by targeting on the potassium channel (Takır et al., 2015), which might be involved in the protective effect of $\mathrm{H}_{2} \mathrm{~S}$ on the retinal vascular diseases.

$\mathrm{DR}$, due to diabetes, is a globally increasingly important retinal disease (Whiting et al., 2011). High glucose-induced retinal microvasculopathy is one of the important causes of reduced visual acuity and acquired blindness. The injured pericytes and capillary blockage due to a high glucose environment, which further leads to generation of vascular endothelial growth factor (VEGF), are the most critically early pathological changes during DR (Lu and Adamis, 2002). The process further leads to the breakdown of the blood-retinal barrier, leakage of retinal capillaries, macular edema, and neovascularization. In streptozotocin-induced diabetic rats, retina $\mathrm{H}_{2} \mathrm{~S}$ level and CSE and 3MST mRNA were decreased. The treatment of NaHS could reduce blood-retinal barrier permeability and acellular capillaries formation in the retina along with the reduced 


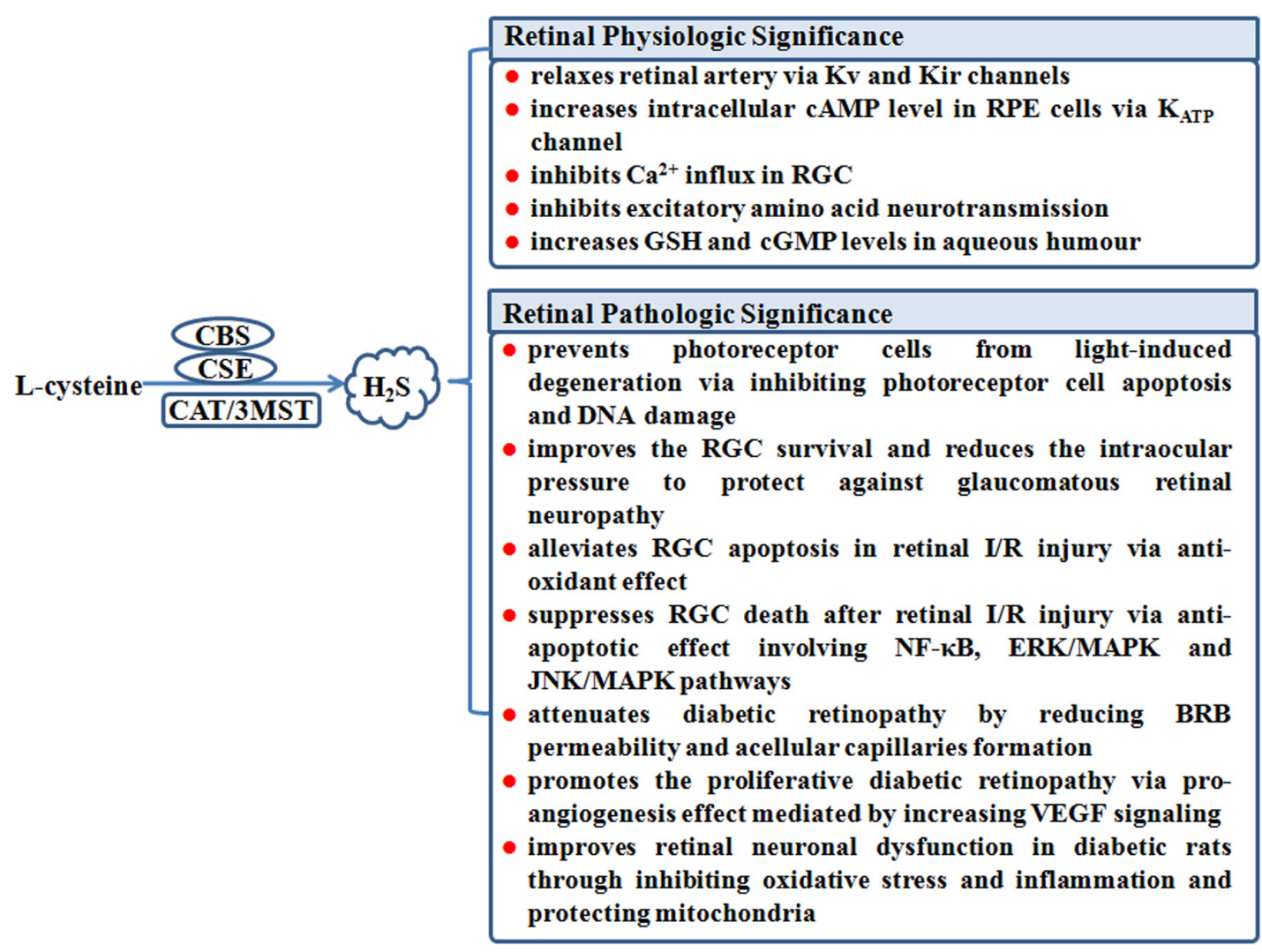

FIGURE 1 | The role of endogenous $\mathrm{H}_{2} \mathrm{~S}$ in the physiologic and pathophysiologic regulation in the retina. 3MST, 3-mercaptopyruvate sulfurtransferase; BRB, blood-retina barrier; cAMP, cyclic adenosine monophosphate; CAT, cysteine aminotransferase; CBS, cystathionine- $\beta$-synthase; cGMP, cyclic guanosine monophosphate; CSE, cystathionine- $\gamma$-lyase; ERK, extracellular signal regulated kinase; GSH, glutathione; $\mathrm{H}_{2} \mathrm{~S}$, hydrogen sulfide; I/R, ischemia/reperfusion; JNK, c-Jun N-terminal kinase; $K_{\text {ATP }}$, ATP-sensitive potassium channel; $\mathrm{K}_{\mathrm{i}}$, inwardly rectifying potassium channel; $\mathrm{K}_{\mathrm{v}}$, voltage-dependent potassium channel; MAPK, mitogen-activated protein kinase; NF-кB, nuclear factor-кB; RGC, retinal ganglion cell; RPE, retinal pigment epithelial; VEGF, vascular endothelial growth factor.

vitreous content of VEGF and its signaling pathway ( $\mathrm{Si}$ et al., 2013), suggesting that retina-derived $\mathrm{H}_{2} \mathrm{~S}$ might protect against high glucose-induced retinal microvasculopathy. However, in another study, $\mathrm{H}_{2} \mathrm{~S}$ was found to play different roles in the development of retinal neovascularization in diabetic patients with proliferative DR (PDR). Ran et al. (2014) revealed that $\mathrm{H}_{2} \mathrm{~S}$ level was increased in both the plasma and the vitreous body of diabetic patients with PDR when compared with that in healthy people and diabetic patients without PDR. In accordance with the increase in $\mathrm{H}_{2} \mathrm{~S}$ level, VEGF levels in the vitreous body from diabetic patients with PDR were also significantly elevated. The above clinical data suggest that $\mathrm{H}_{2} \mathrm{~S}$ might act as a pro-angiogenesis factor to promote the progression of PDR (Ran et al., 2014), which is similar to the role of $\mathrm{H}_{2} \mathrm{~S}$ in the development of angiogenesis in cardiovascular diseases (Cai et al., 2007; Papapetropoulos et al., 2009; Wang et al., 2010). Recently, retina neurodegeneration was found to occur ahead of vascular injury during DR (Aizu et al., 2003; Ozkaya et al., 2017). Si et al. (2013) found that NaHS improved retinal neuronal dysfunction in streptozotocin-treated rats representing the facts that NaHS enhanced b-wave amplitudes and oscillatory potentials. The underlying mechanisms responsible for the neuroprotective effect of $\mathrm{H}_{2} \mathrm{~S}$ in retina included suppressing oxidative stress, protecting mitochondrial function, and inhibiting inflammation. Taken together, $\mathrm{H}_{2} \mathrm{~S}$ plays a complex role in the pathogenesis of DR. Further studies are needed to discover the effect and mechanisms for $\mathrm{H}_{2} \mathrm{~S}$ in DR, which might hopefully deepen the understanding of the DR pathophysiology and help to find new treatments for this disease.

\section{CONCLUSION}

Since $\mathrm{H}_{2} \mathrm{~S}$ and its endogenous synthesis pathway were found in mammalian retina, studies about the effect of $\mathrm{H}_{2} \mathrm{~S}$ on retina physiology and pathology have become a hot topic for ophthalmologists (Figure 1). In the past years, $\mathrm{H}_{2} \mathrm{~S}$ was proved as a neuromodulator in the eye with important effects in some retinal diseases. However, the role of $\mathrm{H}_{2} \mathrm{~S}$ in lots of retinal diseases still needs to be revealed and in-depth studies of the underlying mechanisms are bound to be necessary. As we know, unlike CNS or cardiovascular system, the unique characteristics of retina is the direct connection to the vitreous body, which is a perfect match to gaseous treatment that has been widely used in the 
research of many retina diseases like retinal detachment and macular membrane. Therefore, the $\mathrm{H}_{2} \mathrm{~S}$-related therapy has a bright future but still requires further studies.

\section{AUTHOR CONTRIBUTIONS}

The manuscript was written through contributions of all authors. All authors have given approval to the final version of the manuscript. JD and HJ researched and identified appropriate

\section{REFERENCES}

Abe, K., and Kimura, H. (1996). The possible role of hydrogen sulfide as an endogenous neuromodulator. J. Neurosci. 16, 1066-1071.

Aizu, Y., Katayama, H., Takahama, S., Hu, J., Nakagawa, H., and Oyanagi, K. (2003). Topical instillation of ciliary neurotrophic factor inhibits retinal degeneration in streptozotocin-induced diabetic rats. Neuroreport 14, 20672071. doi: 10.1097/01.wnr.0000097044.56589.78

Archer, D. B. (1976). Tributary vein obstruction: pathogenesis and treatment of sequelae. Doc. Ophthalmol. 40, 339-360. doi: 10.1007/BF0015 5046

Biermann, J., Lagreze, W. A., Schallner, N., Schwer, C. I., and Goebel, U. (2011). Inhalative preconditioning with hydrogen sulfide attenuated apoptosis after retinal ischemia/reperfusion injury. Mol. Vis. 17, 1275-1286.

Bringmann, A., Biedermann, B., Schnurbusch, U., Enzmann, V., Faude, F., and Reichenbach, A. (2000). Age- and disease-related changes of calcium channelmediated currents in human Müller glial cells. Invest. Ophthalmol. Vis. Sci. 41, 2791-2796.

Busskamp, V., Duebel, J., Balya, D., Fradot, M., Viney, T. J., Siegert, S., et al. (2010). Genetic reactivation of cone photoreceptors restores visual responses in retinitis pigmentosa. Science 329, 413-417. doi: 10.1126/science.1190897

Cai, W. J., Wang, M. J., Moore, P. K., Jin, H. M., Yao, T., and Zhu, Y. C. (2007). The novel proangiogenic effect of hydrogen sulfide is dependent on Akt phosphorylation. Cardiovasc. Res. 76, 29-40. doi: 10.1016/j.cardiores.2007. 05.026

Cordeiro, S., Guseva, D., Wulfsen, I., and Bauer, C. K. (2011). Expression pattern of Kv11 (Ether a-go-go-related gene; erg) $\mathrm{K}+$ channels in the mouse retina. PLoS ONE 6:e29490. doi: 10.1371/journal.pone.0029490

Cottet, S., and Schorderet, D. F. (2009). Mechanisms of apoptosis in retinitis pigmentosa. Curr. Mol. Med. 9, 375-383. doi: 10.2174/156652409787847155

Da, C. L., Chen, F. K., Ahmado, A., Greenwood, J., and Coffey, P. (2007). RPE transplantation and its role in retinal disease. Prog. Retin. Eye Res. 26, 598-635. doi: 10.1016/j.preteyeres.2007.07.001

Du, J., Huang, Y., Yan, H., Zhang, Q., Zhao, M., Zhu, M., et al. (2014). Hydrogen sulfide suppresses oxidized low-density lipoprotein (ox-LDL)stimulated monocyte chemoattractant protein 1 generation from macrophages via the nuclear factor кB (NF-кB) pathway. J. Biol. Chem. 289, 9741-9753. doi: 10.1074/jbc.M113.517995

Geng, B., Yang, J., Qi, Y., Zhao, J., Pang, Y., Du, J., et al. (2004). $\mathrm{H}_{2} \mathrm{~S}$ generated by heart in rat and its effects on cardiac function. Biochem. Biophys. Res. Commun. 313, 362-368. doi: 10.1016/j.bbrc.2003.11.130

Gersztenkorn, D., Coletta, C., Zhu, S., Ha, Y., Liu, H., Tie, H., et al. (2016). Hydrogen sulfide contributes to retinal neovascularization in ischemia-induced retinopathy. Invest. Ophthalmol. Vis. Sci. 57, 3002-3009. doi: 10.1167/iovs.1518555

Hall, M. O., Abrams, T. A., and Mittag, T. W. (1993). The phagocytosis of rod outer segments is inhibited by drugs linked to cyclic adenosine monophosphate production. Invest. Ophthalmol. Vis. Sci. 34, 2392-2401.

Hayreh, S. S., Zimmerman, M. B., Kimura, A., and Sanon, A. (2004). Central retinal artery occlusion. Retinal survival time. Exp. Eye Res. 78, 723-736. doi: 10.1016/S0014-4835(03)00214-8

Hosoki, R., Matsuki, N., and Kimura, H. (1997). The possible role of hydrogen sulfide as an endogenous smooth muscle relaxant in synergy with nitric oxide. Biochem. Biophys. Res. Commun. 237, 527-531. doi: 10.1006/bbrc.1997.6878 articles. JD participated in writing the manuscript. HJ and LY revised the manuscript.

\section{FUNDING}

This work was supported by National Natural Science Foundation of China (No. 81670841 and 81470650) and National Program for Support of Top-notch Young Professionals.

Huang, S., Huang, P., Liu, X., Lin, Z., Wang, J., Xu, S., et al. (2017). Relevant variations and neuroprotecive effect of hydrogen sulfide in a rat glaucoma model. Neuroscience 341, 27-41. doi: 10.1016/j.neuroscience.2016.11.019

Hughes, M. N., Centelles, M. N., and Moore, K. P. (2009). Making and working with hydrogen sulfide: The chemistry and generation of hydrogen sulfide in vitro and its measurement in vivo: a review. Free Radic. Biol. Med. 47, 1346-1353. doi: 10.1016/j.freeradbiomed.2009.09.018

Kaneko, Y., Kimura, Y., Kimura, H., and Niki, I. (2006). L-cysteine inhibits insulin release from the pancreatic beta-cell: possible involvement of metabolic production of hydrogen sulfide, a novel gasotransmitter. Diabetes Metab. Res. Rev. 55, 1391-1397. doi: 10.2337/db05- 1082

Kimura, H. (2011). Hydrogen sulfide: its production, release and functions. Amino Acids 41, 113-121. doi: 10.1007/s00726-010-0510-X

Kimura, H., Nagai, Y., Umemura, K., and Kimura, Y. (2005). Physiological roles of hydrogen sulfide: synaptic modulation, neuroprotection, and smooth muscle relaxation. Antioxid. Redox. Signal. 7, 795-803. doi: 10.1089/ars.2005.7.795

Kraus, J. P., and Kozich, V. (2001). "Cystathionine- $\beta$-synthase and its deficiency," in Homocysteine in Health and Disease, eds R. Carmel and D. W. Jacobsen (Cambridge: Cambridge University Press), 223-243.

Kulkarni, M., Njie-Mbye, Y. F., Okpobiri, I., Zhao, M., Opere, C. A., and Ohia, S. E. (2011). Endogenous production of hydrogen sulfide in isolated bovine eye. Neurochem. Res. 36, 1540-1545. doi: 10.1007/s11064-011-0482-6

Kuriyama, S., Hall, M. O., Abrams, T. A., and Mittag, T. W. (1995). Isoproterenol inhibits rod outer segment phagocytosis by both cAMP-dependent and independent pathways. Invest. Ophthalmol. Vis. Sci. 36, 730-736.

Liu, X., Zhang, Y., He, Y., Zhao, J., and Su, G. (2015). Progress in histopathologic and pathogenetic research in a retinitis pigmentosa model. Histol. Histopathol. 30, 771-779. doi: 10.14670/HH-11-596

Low, L., Law, J. P., Hodson, J., McAlpine, R., O’Colmain, U., and MacEwen, C. (2015). Impact of socioeconomic deprivation on the development of diabetic retinopathy: a population-based, cross-sectional and longitudinal study over 12 years. BMJ Open 5:e007290. doi: 10.1136/bmjopen-2014-007290

Lu, M., and Adamis, A. P. (2002). Vascular endothelial growth factor gene regulation and action in diabetic retinopathy. Ophthalmol. Clin. North Am. 15, 69-79. doi: 10.1016/S0896-1549(01)00010-4

Martin, C., Houitte, D., Guillermier, M., Petit, F., Bonvento, G., and Gurden, H. (2012). Alteration of sensory-evoked metabolic and oscillatory activities in the olfactory bulb of GLAST-deficient mice. Front. Neural Circuits 6:1. doi: 10.3389/ fncir.2012.00001

Mikami, Y., Shibuya, N., Kimura, Y., Nagahara, N., Yamada, M., and Kimura, H. (2011). Hydrogen sulfide protects the retina from light-induced degeneration by the modulation of Ca2+ influx. J. Biol. Chem. 286, 39379-39386. doi: 10.1074/jbc.M111.298208

Njie-Mbye, Y. F., Bongmba, O. Y., Onyema, C. C., Chitnis, A., Kulkarni, M., Opere, C. A., et al. (2010). Effect of hydrogen sulfide on cyclic AMP production in isolated bovine and porcine neural retinae. Neurochem. Res. 35, 487-494. doi: 10.1007/s11064-009-0085-7

Njie-Mbye, Y. F., Kulkarni, M., Opere, C. A., and Ohia, S. E. (2012). Mechanism of action of hydrogen sulfide on cyclic AMP formation in rat retinal pigment epithelial cells. Exp. Eye Res. 98, 16-22. doi: 10.1016/j.exer.2012.03.001

Opere, C. A., Monjok, E. M., Kulkarni, K. H., Njie, Y. F., and Ohia, S. E. (2009) Regulation of $[3 \mathrm{H}] \mathrm{D}$-aspartate release from mammalian isolated retinae by hydrogen sulfide. Neurochem. Res. 34, 1962-1968. doi: 10.1007/s11064-0099984-x 
Osborne, N. N., Ji, D., Abdul, M. A., Fawcett, R. J., Sparatore, A., and Del, S. P. (2010). ACS67, a hydrogen sulfide-releasing derivative of latanoprost acid, attenuates retinal ischemia and oxidative stress to RGC-5 cells in culture. Invest. Ophthalmol. Vis. Sci. 51, 284-294. doi: 10.1167/iovs.093999

Ozkaya, A., Alkin, Z., Karakucuk, Y., Karatas, G., Fazil, K., Gurkan, E. M., et al. (2017). Thickness of the retinal photoreceptor outer segment layer in healthy volunteers and in patients with diabetes mellitus without retinopathy, diabetic retinopathy, or diabetic macular edema. Saudi. J. Ophthalmol. 31, 69-75. doi: 10.1016/j.sjopt.2016.12.006

Papapetropoulos, A., Pyriochou, A., Altaany, Z., Yang, G., Marazioti, A., Zhou, Z., et al. (2009). Hydrogen sulfide is an endogenous stimulator of angiogenesis. Proc. Natl. Acad. Sci. U.S.A. 106, 21972-21977. doi: 10.1073/pnas.09080 47106

Pascolini, D., and Mariotti, S. P. (2012). Global estimates of visual impairment: 2010. Br. J. Ophthalmol. 96, 614-618. doi: 10.1136/bjophthalmol-2011300539

Pérez-H, J., Carrillo-S, C., García, E., Ruiz-Mar, G., Pérez-Tamayo, R., and Chavarría, A. (2014). Neuroprotective effect of silymarin in a mptp mouse model of parkinson's disease. Toxicology 319, 38-43. doi: 10.1016/j.tox.2014. 02.009

Perrino, E., Uliva, C., Lanzi, C., Soldato, P. D., Masini, E., and Sparatore, A. (2009). New prostaglandin derivative for glaucoma treatment. Bioorg. Med. Chem. Lett. 19, 1639-1642. doi: 10.1016/j.bmcl.2009.02.007

Pong, W. W., Stouracova, R., Frank, N., Kraus, J. P., and Eldred, W. D. (2007). Comparative localization of cystathionine beta-synthase and cystathionine gamma-lyase in retina: differences between amphibians and mammals. J. Comp. Neurol. 505, 158-165. doi: 10.1002/cne. 21468

Qu, K., Chen, C. P., Halliwell, B., Moore, P. K., and Wong, P. T. (2006). Hydrogen sulfide is a mediator of cerebral ischemic damage. Stroke 37, 889-893. doi: 10.1161/01.STR.0000204184.34946.41

Rajala, R. V., and Rajala, A. (2013). Neuroprotective role of protein tyrosine phosphatase-1B in rod photoreceptor neurons. Protein Cell 4, 890-892. doi: 10.1007/s13238-013-3063-4

Ran, R., Du, L., Zhang, X., Chen, X., Fang, Y., Li, Y., et al. (2014). Elevated hydrogen sulfide levels in vitreous body and plasma in patients with proliferative diabetic retinopathy. Retina 34, 2003-2009. doi: 10.1097/IAE.00000000000 00184

Seki, M., Soussou, W., Manabe, S., and Lipton, S. A. (2010). Protection of retinal ganglion cells by caspase substrate-binding peptide IQACRG rom N-methylD-aspartate receptor-mediated excitotoxicity. Invest. Ophthalmol. Vis. Sci. 51, 1198-1207. doi: 10.1167/iovs.09-4102

Shibuya, N., Koike, S., Tanaka, M., Ishigami-Yuasa, M., Kimura, Y., Ogasawara, Y., et al. (2013). A novel pathway for the production of hydrogen sulfide from D-cysteine in mammalian cells. Nat. Commun. 4:1366. doi: 10.1038/ ncomms 2371
Si, Y. F., Wang, J., Guan, J., Zhou, L., Sheng, Y., and Zhao, J. (2013). Treatment with hydrogen sulfide alleviates streptozotocin-induced diabetic retinopathy in rats. Br. J. Pharmacol. 169, 619-631. doi: 10.1111/bph.12163

Smith, B. J., Côté, P. D., and Tremblay, F. (2017). Contribution of Nav1.8 sodium channels to retinal function. Neuroscience 340, 279-290. doi: 10.1016/j. neuroscience.2016.10.054

Stipanuk, M. H., and Beck, P. W. (1982). Characterization of the enzymic capacity for cysteine desulphhydration in liver and kidney of the rat. Biochem. J. 206, 267-277. doi: 10.1042/bj2060267

Takır, S., Ortaköylü, G. Z., Toprak, A., and Uydeş-Doğan, B. S. (2015). NaHS induces relaxation response in prostaglandin $\mathrm{F}(2 \alpha)$ precontracted bovine retinal arteries partially via Kv and Kir channels. Exp. Eye Res. 132, 190-197. doi: 10.1016/j.exer.2015.02.002

Tang, G., Wu, L., and Wang, R. (2010). Interaction of hydrogen sulfide with ion channels. Clin. Exp. Pharmacol. Physiol. 37, 753-763. doi: 10.1111/j.1440-1681. 2010.05351.x

Wang, M. J., Cai, W. J., Li, N., Ding, Y. J., Chen, Y., and Zhu, Y. C. (2010). The hydrogen sulfide donor NaHS promotes angiogenesis in a rat model of hind limb ischemia. Antioxid. Redox Signal. 12, 1065-1077. doi: 10.1089/ars.2009. 2945

Wenzel, A., Grimm, C., Samardzija, M., and Reme, C. E. (2005). Molecular mechanisms of light-induced photoreceptor apoptosis and neuroprotection for retinal degeneration. Prog. Retin. Eye Res. 24, 275-306. doi: 10.1016/j.preteyeres. 2004.08.002

Whiting, D. R., Guariguata, L., Weil, C., and Shaw, J. (2011). IDF diabetes atlas: global estimates of the prevalence of diabetes for 2011 and 2030. Diabetes. Res. Clin. Pract. 94, 311-321. doi: 10.1016/j.diabres.2011.10.029

Wimmers, S., Karl, M. O., and Strauss, O. (2006). Ion channels in the RPE. Prog. Retin. Eye Res. 26, 263-301. doi: 10.1016/j.preteyeres.2006.12.002

Zhang, H., Wong, C. L., Shan, S. W., Li, K. K., Cheng, A. K., Lee, K. L., et al. (2011). Characterisation of $\mathrm{Cl}^{-}$transporter and channels in experimentally induced myopic chick eyes. Clin. Exp. Optom. 94, 528-535. doi: 10.1111/j.1444-0938. 2011.00611.x

Zhao, W., Zhang, J., Lu, Y., and Wang, R. (2001). The vasorelaxant effect of H2S as a novel endogenous gaseous $\mathrm{K}_{\mathrm{ATP}}$ channel opener. EMBO J. 20, 6008-6016. doi: $10.1093 / \mathrm{emboj} / 20.21 .6008$

Conflict of Interest Statement: The authors declare that the research was conducted in the absence of any commercial or financial relationships that could be construed as a potential conflict of interest.

Copyright (c) 2017 Du, Jin and Yang. This is an open-access article distributed under the terms of the Creative Commons Attribution License (CC BY). The use, distribution or reproduction in other forums is permitted, provided the original author(s) or licensor are credited and that the original publication in this journal is cited, in accordance with accepted academic practice. No use, distribution or reproduction is permitted which does not comply with these terms. 